\title{
Peertechz
}

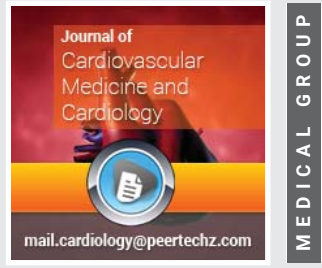

\section{Resveratrol and spirulina: Nutraceuticals that potentially improve cardiovascular disease}

\author{
Yifan Wang ${ }^{1,2}$, Maria Fides Ocampo ${ }^{1,3}$, Bianca Rodriguez ${ }^{1,3}$ \\ and Jiwang Chen ${ }^{1,3 *}$
}

${ }^{1}$ College of Pharmacy, Department of Medicine, Research Resources Center, University of Illinois at Chicago, Chicago, IL, USA

${ }^{2}$ Division of Pulmonary and Critical Care Medicine, Sleep and Allergy, University of Illinois at Chicago, Chicago, IL, USA

${ }^{3}$ Cardiovascular Research Center, Department of Medicine, Research Resources Center, University of Illinois at Chicago, Chicago, IL, USA

Received: 12 May, 2020

Published: 25 May, 2020

*Corresponding author: Jiwang Chen, PhD, Director of Cardiovascular Research Core, Research Resources Center, University of Illinois at Chicago, $835 \mathrm{~S}$ Wolcott Ave, MSB, Suite E102, MC937, Chicago, IL 60612, USA, Tel: 312-355-2918 ; Fax: 312-996-0539;

E-mail: chenjw@uic.edu

Keywords: Resveratrol; Spirulina; Cardiovascular diseases; Dietary; Reviews

https://www.peertechz.com

\section{Check for updates}

\begin{abstract}
Resveratrol (3,5,4'-trihydroxy-trans-stilbene) is an extensively studied nutraceutical with several proposed health benefits, including cardio protection, antimetabolic syndrome, and antiatherogenic effects. It was brought to popularity through the proposed "French Paradox" and the consumption of red wine. It has been shown to down regulate the activation of numerous inflammatory and oxidative stress markers with therapeutic potentials. Spirulina (Arthrospira platensis), on the other hand, is a highly nutritional nutraceutical that has not been sufficiently studied. However, several in vitro and animal studies point to its hypolipidemic and antihypertensive properties, which are similar to resveratrol. Although resveratrol and Spirulina both constitutes functional foods with potential therapeutic effects on several cardiovascular diseases, there are few compelling clinical evidence to support their applications in human patients. This warrant further evaluation in clinical trials. This article reviews and evaluates the beneficial effects of the two different nutraceuticals in order to demonstrate their potential in clinical application in patients with cardiovascular diseases.
\end{abstract}

\section{Introduction}

Cardiovascular Disease (CVD) is a preventable condition defined by a range of disease states involving the heart and blood vessels. It is the leading cause of death in the U.S. and most developed countries. Cardiovascular disease affects millions of Americans daily, and on average, a patient dies of CVD every 38 seconds, amounting to 2,303 deaths daily based on 2016 data [1]. Coronary Artery Disease (CAD), a type of atherosclerotic cardiovascular disease, is the most common type of CVD, which is characterized by endothelial dysfunction resulting from atherosclerosis and occlusion by fatty plaque. Hypertension is the most common and insidious type of modifiable CVD. The American Heart Association predicts 116.4 million of American adults have hypertension in 2019 [2]. People at high risk for CVD can modify their clinical outcome through exercising, smoking cessation, controlled hypertension and blood glucose level, and dietary changes. Dietary modifications have always been an effective primary prevention for people with chronic cardiovascular conditions. We have chosen to closely examine two dietary supplements - Resveratrol and Spirulina - due to their widespread popularity in the nutraceutical market as well as the research communities.

Chemical compound 3,5,4'-trihydroxy-trans-stilbene, commonly known as resveratrol, is a naturally occurring polyphenolic, non-flavonoid antioxidant that can be extracted from numerous fruit and plant sources [3]. Polyphenols have been extensively studied for their health benefits and is thought to be partially responsible for the "French Paradox", an epidemiological phenomenon from early nineties in which certain populations of France have shown to be less 
predisposed to cardiovascular diseases despite a high fat diet and low exercise level due to a moderate consumption of red wine [4]. The precise mechanism of this occurrence has yet to be identified, and the low concentration of resveratrol in red wine may suggest a debatable efficacy. Nonetheless, resveratrol studies have demonstrated various intracellular activities of the compound that may lead to further biological and pharmaceutical applications.

Spirulina is a cyanobacteria that is grown into two species - maxima and plantesis. Stemming from bluegreen algae, spirulina emerges from alkaline lakes with high concentrations of carbonate and bicarbonate, and is produced for supplementation in large numbers in outdoor or greenhouse ponds $[5,6]$. Spirulina has been widely cultivated due to its massive nutritional value, consisting of $70 \%$ vitamins (including B12 and provitamin A), minerals, and fatty acids. Although no adverse effects have been found from spirulina, there are possibilities of toxic effects would derive from the heavy metals found in the outdoor or greenhouse ponds. Sufficient studies have not been performed in order to make a strong assumption that spirulina has minimal to no toxic effects. Spirulina is currently marketed as a supplement for its high antioxidant, anti-inflammatory, immunomodulatory, and hyperlipidemia activities. Research shows spirulina's manifold activities has proven favorable in the prevention and treatment of CVD [7].

There are significant differences in their pharmacokinetic profiles, but both spirulina and resveratrol exhibit similar benefits. Many researches were performed to provide evidence for these claims. Due to their diverse activities, researchers speculate resveratrol and spirulina can be used as supplements for patients with different types of CVD as potential prevention and treatment options.

It has been proven that certain "superfoods" can affect the progression of these diseases. Due to public demands, there has been a substantial growth over the past decades in the application of nutraceuticals, or bio-ceuticals, due to increasing drug resistance and costs. Although some argue that nutraceuticals are largely unregulated by the U.S. law, a notable number of studies have been dedicated to the investigation and analysis of the therapeutic claims of these substances. These claims are often not unfounded. Although pharmaceutical intervention is proven to be highly efficacious for the management of CVD, this paper will be focused on the proposed cardioprotective benefits between two nutraceuticals that both have significant antioxidant power and similar therapeutic properties.

\section{Pharmacology and biology}

Resveratrol: Resveratrol is produced as a natural product in a wide variety of plant and food sources such as grapes, peanuts and different types of berries. It was first isolated in 1940 from Veratrum Grandiflorum, and later also identified in traditional Japanese and Chinese medicine as Ko-jo-kon [8]. It is synthesized through the enzyme stilbene synthase, which is activated primarily as a defense mechanism against exogenous stress factors such as microbial infection and inadequate nutrition $[9,10]$. Both cis- and trans- resveratrol are found in nature, and while the trans- isoform is responsible for desired activity level, cis-resveratrol can be rapidly converted into trans-resveratrol under low $\mathrm{pH}$ environment, such as the human gastrointestinal tract [11]. Resveratrol exhibits low solubility and are highly protein bound, which leads to trace amounts of free and unchanged resveratrol in systemic circulation $[12,13]$. Resveratrol has been observed to exhibit optimal activity at lower doses and less activity at higher doses, which can be defined as hormetic [14]. Adverse reactions and toxicities to resveratrol are mild and rare, but it has been recommended to avoid doses of resveratrol higher than 1,000 $\mathrm{mg} /$ day due to drug interactions with CYP-P450 enzymes [15]

Enteral administration of resveratrol leads to intense hepatic metabolism through phase II reactions and bacterial metabolism in the gut flora, which explains the low bioavailability (1\%) of resveratrol despite fast absorption after ingestion $[16,17]$. The compound also undergoes enterohepatic recirculation. Seven resveratrol metabolites have been identified so far, including dihydro-resveratrol, glucuronide, and sulfate metabolites [18]. It has been suggested that these metabolites are biologically active through in vitro and in vivo experiments. In terms of CYP-P450 enzymes, resveratrol was shown to be an inducer of CYP1A2 while simultaneously inhibiting CYP3A4, CYP2D6, and CYP2C9 [19]. It also exhibits minimal interactivity with phase II detoxification enzymes [20]. This may also lead to significantly different pharmacokinetic profiles between individuals with dissimilar hepatic functions and microbiota.

In theory, improvement of water solubility and drug delivery mechanism may significantly enhance the bioavailability of resveratrol. Enormous efforts have been put into the research of a delivery system that may facilitate its absorption. Lipid-based vehicle, such as nanoparticles and liposomes have been demonstrated to enhance solubility and stability of resveratrol without any cellular toxicity [21,22]. Nano emulsions that encapsulate resveratrol can also enhance cellular uptake and membrane transport, which increase the plasma concentration and oral bioavailability [23]. Pectinate beads with Zinc and Calcium have shown improved absorption in both invitro and in vivo studies [24,25]. In addition to drug delivery systems, chemical modifications of resveratrol such as methoxylation, hydroxylation, and halogenation have demonstrated enhancement in pharmacokinetic profile [26]. Resveratrol analogues such as pterostilbene and piceatannol display similar therapeutic profile with increased biological activity $[27,28]$. The structures of resveratrol and its analogues have been demonstrated.

Spirulina and components: Spirulina is a prokaryotic cyanobacteria derived from Arthrospira. It is a sustainable and environmentally friendly biomass of plant material that is both highly nutritious and cost effective. Spirulina is made up of many biopolymers, lipids, minerals, sterols, vitamins, and proteins [6]. It contains several functional compounds that contribute to its antioxidant, anti-inflammatory and immunostimulant potential, such as flavonoids, phenols and polysaccharides [29]. The 3 essential active ingredients this 
paper will discuss are phycocyanin, phycocyanobilin, and $\beta$-carotene. Spirulina itself also has no toxic or teratogenic properties.

Phycocyanin belongs to a group called phycobiliproteins, which are proteins present in cyanobacteria and capture light to be passed onto chlorophylls during photosynthesis. The structure is similar to bilirubin, giving its antioxidant properties [30]. Bilirubin is a pigment found in bile from the breakdown of hemoglobin that gives bile its orange-yellow hue [31]. Bilirubin has been found to have effective antioxidant activity by inhibiting oxidation and radical byproducts in plasma proteins and aromatic amino acid residues.

Stemming from mesobiliverdin, phycocyanobilin is an isomer of this compound [32]. It is currently used as food coloring and is present in the chromophore of phycocyanin. It makes up the non-protein portion of phycocyanin with its open chain tetrapyrrole. Structurally, phycocyanin is similar to biliverdin, which is another pigment but for bile instead. Because of the structural similarities, phycocyanobilin can be metabolized by biliverdin reductase, forming its reduced state, phycocyanobilin. Phycocyanobilin also has strong antioxidant and anti-inflammatory properties by actively inhibiting NADPH oxidase, which is a major cause of oxidative stress.

$\beta$-carotene is a non-oxygenated, provitamin A carotenoid that is not water soluble [33]. It is the most abundant carotenoid present in the human diet. It is metabolized through cleavage by $\beta$-carotene-15,15'-oxygenase, and the body expresses copious amounts of these enzymes. However, the conversion of all $\beta$-carotene to vitamin $A$ is not feasible. It is absorbed in the small intestine and from there, delivered to the peripheral tissue. Stores of $\beta$-carotene are saved in tissues of the body such as the kidneys, adipose tissue, and lungs.

Spirulina is unique in its structure as it has multicellular cylindrical trichomes, which forms small outgrowths from its body [34]. These trichomes are in open left-handed helix throughout its frame, and because of the characteristic structure with its trichomes, spirulina creates its own genus with the helical shape. Additionally, the species differs between the genus by the length and size of the helix. It was given its name due to the spiral movement of the filament and trichomes. Spirulina can supply their own food via photosynthesis, making them autotrophs. The structures of Spirulina's components have been demonstrated.

\section{Pathophysiology/Molecular targets}

-Resveratrol: The pathogenesis of atherosclerotic cardiovascular diseases mainly involves arterial remodeling developed from the formation of fatty streaks and atherosclerotic plaques which may eventually rupture and trigger a thrombotic cascade, leading to further complications involving vital organs $[35,36]$. This process is principally mediated by excess in low density lipoproteins and inflammation, which occurs from vasoconstriction from increased endothelin, decreased Nitric Oxide, and macrophage accumulation in the vessel. It has been previously discovered that resveratrol exerts effects on multiple anti-inflammatory targets involved in the atherosclerosis disorder, such as C-reactive protein (CRP) and $\mathrm{N}$-terminal pro brain natriuretic peptide (NT-proBNP) $[37,38]$. These biomarkers are also related to inflammation and cardiovascular functions.

Low grade inflammation has also been associated with CVD development. Resveratrol affects several molecular targets related to potential benefits of cardio protection. Resveratrol increase NO bioavailability, decrease tumor necrosis factor alpha (TNF a), inhibits NADPH oxidase and mitochondrial reactive oxygen species activity $[39,40]$. The downgrade of these targets suggests that resveratrol acts as an antiinflammatory agent in age associated inflammation.

Inflammation can be caused by the overproduction of mitochondrial reactive oxygen species as well as heightened NADPH oxidase activity. This creates more vascular oxidative stress, causing the tissue to inflame [41]. Nitric oxide, an essential substance produced by the body, is a potent vasodilator. It helps to increase blood flow to specific areas and maintain endothelial cell function [42]. When the body ages, NADPH oxidase activity begins to increase, which causes more reactive oxygen species production as well as nitric oxide inactivation [43]. Through this series of events, inflammation begins to be more prominent.

Resveratrol downgrades COX-2 activity, which restricts inflammation caused by prostaglandin since COX-2 catalyzes prostaglandin production [44]. Resveratrol also inhibits vasoconstrictor endothelin-1 via regulation of extracellular signal-regulated kinase $1 / 2$ pathway, which is a factor in endothelial remodeling and thrombosis [45]. Resveratrol was found to exert a protective effect on cardiomyocytes through inhibition of reactive oxygen species via SIRT1 expression, which reduce oxidative stress, apoptosis, and myocardial hypertrophy but promote vasodilation [46].

-Spirulina: Preclinical trials found a significant increase in lipase activity after ingestion of spirulina, which is theorized to help with hyperlipidemia [47]. However, the exact mechanism of action for this effect is still being investigated. One interesting speculation is that spirulina binds to cholesterol metabolites and bile acids, causing an increase in fecal excretion of these metabolites. This, in theory, would decrease serum cholesterol levels. Some reports also suggest that the cholesterol effects may have come from C-phycocyanin activities [30]. The proposed mechanism pathway of resveratrol has been demonstrated.

One potential target that spirulina targets is TNF-a, which is a well-known proinflammatory signaling protein. In addition, the c-phycocyanin, the protein mentioned previously, targets and inhibits the nuclear factor-kappa B (NF-kB) pathway in particular [48]. As a result, TNF-a along with other inflammatory signaling proteins (IL-6, IL$8, \mathrm{IL}-1 \mathrm{~B})$ are not generated, thereby halting the final stages leading to inflammation. Innate immunity was not affected as studies showed that the macrophage activity was undisturbed with spirulina consumption. This gives spirulina its antiinflammatory properties. The proposed mechanism pathway of spirulina has been demonstrated. 
C-phycocyanin also shows antioxidant activity. It inhibits enzymes such as cyclooxygenase-2 (COX-2) and inducible nitric oxide synthase (iNOS) in a similar fashion to resveratrol [44]. COX-2 is a prooxidant enzyme that helps to develop the oxygenation of arachidonic acid, which leads to biological responses including pain, anxiety, and inflammation. Nonetheless, by inhibiting COX-2, spirulina helps to reduce these biological responses.

Effects of resveratrol and spirulina have been shown on a cellular level in multiple literatures. Additional research on human and animal models are needed to fully explore these potential targets.

\section{Resveratrol and Spirulina in CVD with clinical evidence}

The cardioprotective effect of resveratrol and spirulina can be supported with multiple clinical trials that explore its potential in the treatment of CVD. For the most part, human clinical trial results are consistent with preclinical animal studies, which validates the efficacy of utilizing resveratrol for primary prevention. For the purpose of this paper, cardiovascular protective capacities of resveratrol and spirulina are examined through their effectiveness as therapeutic intervention of hypertension, hyperlipidemia, and metabolic syndrome in clinical trials

In Caucasian patients with a history of myocardial infarction and coronary artery disease diagnosed through angiography, daily oral administration of $10 \mathrm{mg}$ resveratrol for 3 months showed to increase flow-mediated vasodilation and left ventricular diastolic function while lowering LDL-cholesterol level compared to placebo [49].

In overweight adult patients with a history of angina pectoris on stable treatment for at least 1-month, oral administration of $20 \mathrm{mg}$ resveratrol daily for 2 months significantly lowered HsCRP and NT-proBNP compared to calcium fructoborate with a favorable trend in the lipid profile [50].

In adult patients with type 2 diabetes with at least 6 months of anti-diabetic treatment and not taking any antioxidant supplements, daily enteral administration of 1000 $\mathrm{mg}$ resveratrol for 45 days significantly reduced systolic blood pressure and LDL while increasing HDL compared to placebo. Another study with the same inclusion criteria for subjects was performed with daily oral administration of $250 \mathrm{mg}$ resveratrol. After 3 months, the resveratrol group revealed a decrease in systolic blood pressure, LDL, and total cholesterol count compared to the placebo group [51].

In another study performed by Martinez-Samano et al, a pilot clinical trial with only 16 patients ( 8 in each treatment group) was executed to determine if Spirulina maxima has beneficial blood pressure effects on patients with systemic arterial hypertension (SAH) that are undergoing angiotensin converting enzyme inhibitor (ACE-I) treatment [52]. According to the results, systolic blood pressure changes were only statistically significant after 12 weeks post-start, and no statistically significant results were seen in the diastolic blood pressure changes. The only conclusion agreed upon was the add-on effects on spirulina for the treatment of SAH. No further statements were made on the prevention nor solo treatment for SAH with spirulina.

In a preliminary report, 36 patients (between 18-65 years old) were treated with $4.5 \mathrm{~g}$ /day by mouth of Spirulina maxima for 6 weeks with no modifications to diet or lifestyle [53]. Statistically significant differences were seen in triglycerides, HDL-C, and LDL-C values. The authors concluded that Spirulina maxima had beneficial effects on hyperlipidemia; however, Spirulina maxima showed indirect effects on HDL-C and TC concentrations. Nonetheless, the authors deemed Spirulina maxima as a treatment in patients with a milder case of hypercholesterolemia. Clinical significance was not concluded for Spirulina maxima for lowering properties as it is not as aggressive as pharmacological options.

Alternatively, New Zealand White rabbits were subjects in testing Spirulina platensis in preventing atherosclerosis [54]. After 8 weeks of treatment with spirulina, the atherosclerotic lesions that were induced by the hypercholesterolemia diets were significantly improved. The conclusion stated Spirulina platensis has protective properties against atherosclerosis and can be used as a functional food to help improve cholesterol levels and prevent atherosclerosis from progressing. It remains unclear the exact mechanisms of how Spirulina platensis is capable of such claims.

\section{Dietary suggestions}

Resveratrol doses vary greatly on the market, and doses as high as $2000 \mathrm{mg} / \mathrm{kg} /$ day were used in clinical studies $[55,56]$. Dosing for resveratrol is still a controversial subject, since most research studies use vastly different doses. Studies are inconsistent regarding the beneficial effects of resveratrol. Differences in clinical trials are due to lack of understanding of the pharmacokinetic, bioavailability, and individual differences. Most supplements on the market contain too little resveratrol to exert any physiological effects. We have found that the New York Academy of Sciences recommended taking at least 500 $\mathrm{mg}$ of resveratrol a day [57]. Major daily sources of dietary resveratrol include wine, grapes, dark chocolate, apples, soy, and Itadori tea [58]. Resveratrol intake level is highly variable across different countries and different climates. Concentration of resveratrol can be affected by various exogenous and endogenous factors, such as temperature and pH level [59].

Studies varied about dosing for spirulina. Many clinical studies used between 1-4 g/day, but some even went as high as $10 \mathrm{~g}$. Most over-the-counter supplementations recommend $500 \mathrm{mg}$ to $4 \mathrm{~g}$ per the bottle label $[60,61]$. The ranges of recommended doses differ between the use of the nutraceutical (blood glucose control vs. hypertension); thus, it is recommended to consult a pharmacist or primary care physician to seek all appropriate options. It should also be noted that spirulina has not been studied as to whether it should be taken multiple times in a day nor in smaller doses [62]. The safety and efficacy of both supplements have only been used in the studies for adult population, and the safety of taking these two supplements at the same time has not been studied adequately [63].

Citation: Wang Y, Ocampo MF, Rodriguez B, Chen J (2020) Resveratrol and Spirulina: Nutraceuticals that Potentially Improve Cardiovascular Disease. J Cardiovasc Med Cardiol 7(2): 138-145. DOI: https://dx.doi.org/10.17352/2455-2976.000129 


\section{Conclusion}

Literatures have proven the diverse effects of resveratrol and spirulina. They are shown to have therapeutic effects in many different disease states with multiple molecular targets. They both exert anti-inflammatory, anti-oxidation, and antidiabetic effects. It is possible that these nutraceuticals will play a bigger role in the prevention and treatment CVD and
T2DM after further research. Preclinical data on spirulina and resveratrol have been controversial, with both promising and discouraging results. This difference may be attributed to different study designs and populations, as well as low absorption and bioavailability.

Nonetheless, more extensive and methodological studies are required if we want to utilize the perceived amazing<smiles>Oc1ccc(CCc2cc(O)cc(O)c2)cc1</smiles>

Resveratrol<smiles>COc1cc(/C=C/c2ccc(O)cc2)cc(OC)c1</smiles>

Pterostilbene<smiles>Oc1cc(O)cc(C=Cc2ccc(O)c(O)c2)c1</smiles>

Piceatannol<smiles>C=C1NC(=O)C(C)=C1CCSCCC(NC)C(=O)O</smiles>

Phycocyanin

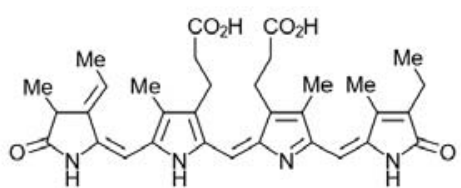

Phycocyanobilin

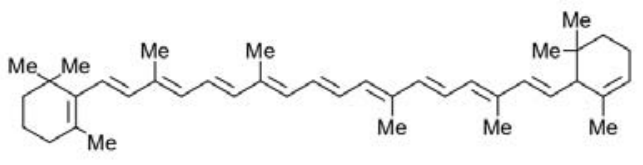

$\beta$-Carotene

Figure 1: Resveratrol structure and its analogues: pterostilbene and piceatannol, along with spirulina's components: phycocyanin, phycocyanobilin, and $\beta$-carotene.

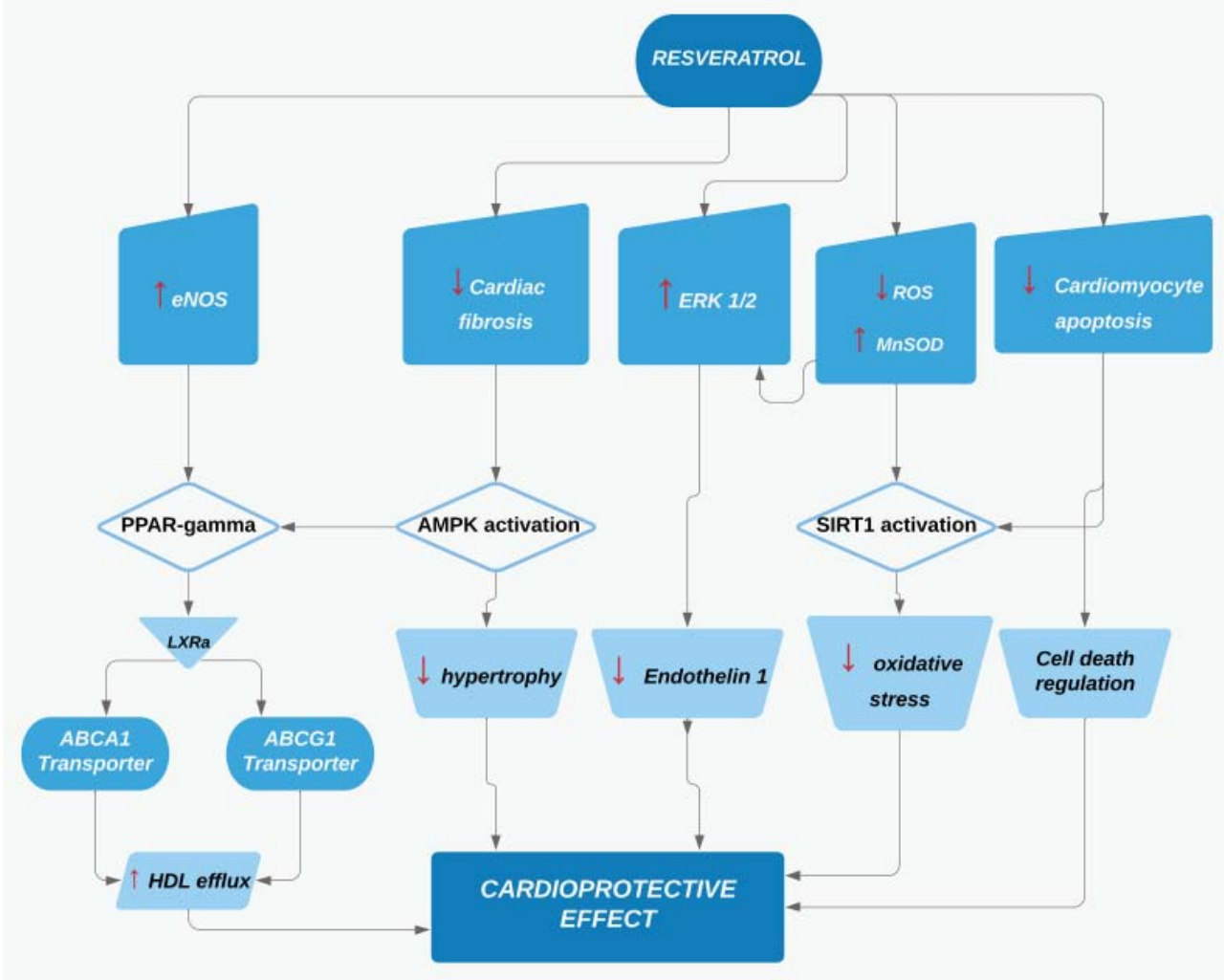

Figure 2: Illustration of the proposed mechanism of cardioprotective effects of resveratrol. Resveratrol effects eNOS, AMPK, PPAR-gamma, SIRT1, ABCA1 and ABCG transporter, and ERK1/2. This results in decreased hypertrophy, oxidative stress, and cardiac fibrosis[62]. We referred the findings from Cho et al (2017) [62] 


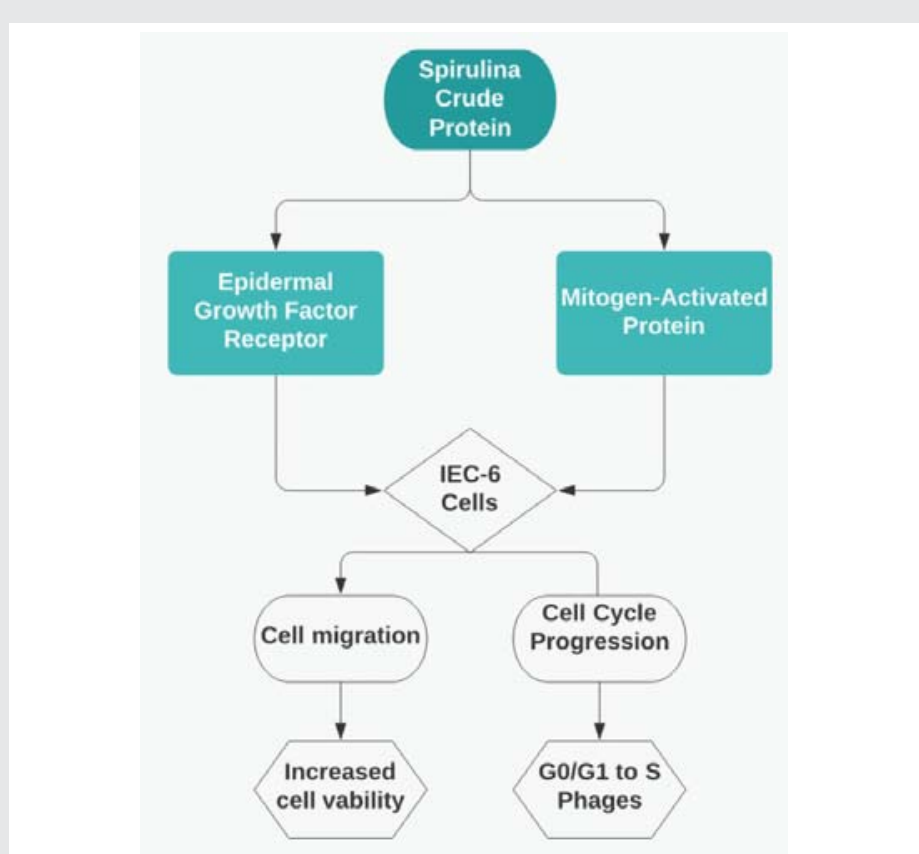

Figure 3: Illustration of the proposed mechanism of action for spirulina. Spirulina promotes cell migration and progression through activation of IEC- 6 cells by phosphorylation of epidermal growth factor receptor and mitogen-activated protein [63]

benefits of resveratrol and spirulina. There are currently few ongoing trials that may expand our understanding on the subjects. Further research on resveratrol should be aimed on increasing its bioavailability and pharmacokinetic profile. Studies should focus on using resveratrol and its analogues as scaffold compounds for the possible development of synthetic medications. Similarly, not enough studies have been performed to prove spirulina's full potential. Although some clinical studies exist, their small population size along with limited data delegitimizes their findings. As mentioned previously, studies using spirulina had varying doses of spirulina, making it difficult to decipher as to proper dosage to see clinically significant results. Therefore, spirulina has been recommended to take at different doses for different indications. With more evidence-based studies, clinicians will feel more comfortable endorsing spirulina to ensure the safety and efficacy for the patient. To conclude, resveratrol and spirulina have shown potential in proving their beneficial effects as supplements and add-on therapies, but their roles to replace pharmacological treatments are questionable and controversial.

\section{References}

1. Heart Disease Facts (2019) Centers for Disease Control and Prevention. Link: https://bit.ly/36qY7UI

2. Coronary Artery Disease (2019) Centers for Disease Control and Prevention. Link: https://bit.ly/3cWgGCZ

3. Gambini J, López-Grueso R, Olaso-González G, Inglés M, Abdelazid K, et al (2013) Resveratrol: distribution, properties and perspectives. Rev Esp Geriatr Gerontol 48: 79-88. Link: https://bit.ly/36mkGKv

4. Renaud S, de Lorgeril M (1992) Wine, alcohol, platelets, and the French paradox for coronary heart disease. Lancet 339: 1523-1526. Link: https://bit.ly/2A6U5EU

5. Karkos PD, Leong SC, Karkos CD, Sivaji N, Assimakpoulos DA (2011) Spirulina in Clinical Practice: Evidence-Based Human Applications. Evid Based Complement Alternat Med 2011. Link: https://bit.ly/3ghZSIH

6. Wu Q, Liu L, Miron A, Klímová B, Wan D, et al. (2016) The antioxidant immunomodulatory, and anti-inflammatory activities of Spirulina: an overview. Arch. Toxicol 90: 1817-1840. Link: https://bit.ly/2Zux3mk

7. Lietstianty D, Rodianawati I, Arfah RA, Assa A, Patimah et al. (2019) Nutritional Analysis of Spirulina sp. to Promote as Superfood Candidate. Materials Science and Engineering 1-6. Link: https://bit.ly/3ghJV52

8. Aggarwal BB, Bhardwaj A, Aggarwal RS, Seeram NP, Shishodia S, et al. (2004) Role of resveratrol in prevention and therapy of cancer: Preclinical and clinical studies. Anticancer Res 24: 2783-2840. Link: https://bit.ly/3easTUI

9. Stervbo U, Vang O, Bonnesen C (2007) A review of the content of the putative chemopreventive phytoalexin resveratrol in red wine. Food Chem 101: 449457. Link: https://bit.ly/3eeHyOW

10. Fornara V, Onelli E, Sparvoli F, Rossoni M, Aina R, et al. (2008) Localization of stilbene synthase in Vitis vinifera L. during berry development. Protoplasma 233: 83-93. Link: https://bit.ly/2yw3QMK

11. Trela BC, Waterhouse AL (1996) Resveratrol: Isomeric molar absorptivities and stability. J Agric Food Chem 44: 1253-1257. Link: https://bit.ly/2Tv96Yj

12. Khan MA, Muzammil S, Musarrat J (2002) Differential binding of tetracyclines with serum albumin and induced structural alterations in drugbound protein Int J Biol Macromol 30: 243-249. Link: https://bit.ly/2AORK1S

13. Jannin B, Menzel M, Berlot JP, Delmas D, Lancon A, et al. (2004) Transport of resveratrol, a cancer chemopreventive agent, to cellular targets: plasmatic protein binding and cell uptake. Biochem Pharmacol 68: 1113-1118. Link: https://bit.ly/3cZxiJV

14. Juhasz B, Mukherjee S, Das DK (2010) Hormetic response of resveratrol against cardioprotection. Exp Clin Cardiol 15: e134-e138. Link: https://bit.ly/2LRzPtJ

15. Salehi B, Mishra AP, Nigam M, Sener B, Kilic M, et al. (2018) Resveratrol: A Double-Edged Sword in Health Benefits. Biomedicines 6: 91. Link: https://bit.ly/2zd8AHv

16. Marier JF, Vachon P, Gritsas A, Zhang J, Moreau JP, et al. (2002) Metabolism and disposition of resveratrol in rats: Extent of absorption, glucuronidation, and enterohepatic recirculation evidenced by a linked-rat model. J Pharmacol Exp Ther 302: 369-373. Link: https://bit.ly/2TyWz5U

17. Walle T, Hsieh F, DeLegge MH, Oatis JE, Walle UK (2004) High absorption but very low bioavailability of oral resveratrol in humans. Drug Metab Dispos 32: 1377-1382. Link: https://bit.ly/2LW3cuM

18. Boocock DJ, Patel KR, Faust GES, Normolle DP, Marczylo TH, et al. (2007) Quantitation of trans-resveratrol and detection of its metabolites in human plasma and urine by high performance liquid chromatography. J Chromatogr B 848: 182-187. Link: https://bit.ly/2WV4ht7

19. Piver B, Berthou F, Dreano Y, Lucas D (2001) Inhibition of CYP3A, CYP1A and CYP2E1 activities by resveratrol and other non volatile red wine components. Toxicol Lett 125: 83-91. Link: https://bit.ly/2AVQpXh

20. Kaldas MI, Walle UK, Walle T (2003) Resveratrol transport and metabolism by human intestinal Caco-2 cells. J Pharm Pharmacol 55: 307-312. Link: https://bit.ly/2XmW007

21. Caddeo C, Teskac K, Sinico C, Kristl J (2008) Effect of resveratrol incorporated in liposomes on proliferation and UV-B protection of cells. Int J Pharm 363: 183-191. Link: https://bit.ly/3gg4Sxh

22. Coimbra M, Isacchi B, van Bloois L, Torano JS, Ket A, et al. (2011) Improving solubility and chemical stability of natural compounds for medicinal use by incorporation into liposomes. Int J Pharm 416: 433-442. Link: https://bit.ly/3bW85if 
23. Teskac K., Kristl J (2010) The evidence for solid-lipid nanoparticles mediated cell uptake of resveratrol. Int J Pharm 390: 61-69. Link: https://bit.ly/2TxyWux

24. Das S, Ng KY (2009) Resveratrol-Loaded Calcium-Pectinate Beads: Effects of Formulation Parameters on Drug Release and Bead Characteristics. J Pharm Sci 99: 840-860. Link: https://bit.ly/2ZwxDQq

25. Das S, Ng KY, Ho PC (2010) Formulation and optimization of zinc-pectinate beads for the controlled delivery of resveratrol. AAPS Pharm Sci Tech 11: 729 724. Link: https://bit.ly/2LTzIDC

26. Qing-Shan Li, Yao Li, Deora GS, Ruan BF (2019) Derivatives and Analogues of Resveratrol: Recent Advances in Structural Modification. Mini Rev Med Chem 19: 809-825. Link: https://bit.ly/2Xm1tob

27. Wang P, Sang S (2018) Metabolism and pharmacokinetics of resveratrol and pterostilbene. Biofactors 44: 16-25. Link: https://bit.ly/2XmV1Nt

28. Nawaz W, Zhou Z, Deng S, Ma X, Ma X, et al. (2017) Therapeutic Versatility of Resveratrol Derivatives. Nutrients 9: 1188. Link: https://bit.ly/3bYhCFk

29. Park WS, Kim HJ, Li M, Lim DH, Kim J, et al. (2018) Two Classes of Pigments, Carotenoids and C-Phycocyanin, in Spirulina Powder and Their Antioxidant Activities. Molecules 23: 2065. Link: https://bit.ly/3gflzbe

30. Romay Ch, González R, Ledón N, Remirez D, Rimbau V (2003) C--phycocyanin: A Biliprotein with Antioxidant, Anti-Inflammatory and Neuroprotective Effects. Curr Protein Pept Sci 4: 207-216. Link: https://bit.ly/2ZtySQk

31. Sticova E, Jirsa M (2013) New insights in bilirubin metabolism and their clinical implications. World J Gastroenterol 19: 6398-6407. Link: https://bit.ly/2zd1209

32. Liwa AC, Barton EN, Cole WC (2017) Bioactive Plant Molecules, Sources and Mechanism of Action in the Treatment of Cardiovascular Disease. Pharmacognosy Fundamentals, Applications and Strategies 315-336

33. Shete V, Quadro L (2013) Mammalian metabolism of $\beta$-carotene: gaps in knowledge. Nutrients 5: 4849-4868. Link: https://bit.ly/2Zxjjai

34. Morais M, Vaz B, Morais E, Costa J (2014) Biological Effects of Spirulina (Arthrospira) Biopolymers and Biomass in the Development of Nanostructured Scaffolds. BioMed Research International 1-9. Link: https://bit.ly/2yqomOE

35. Ross R (1999) Atherosclerosis-an inflammatory disease. N Engl J Med 340: 115-126. Link: https://bit.ly/3ghNKXR

36. Atherosclerotic Cardiovascular Disease (1989) National Research Council (US) Committee on Diet and Health. Diet and Health: Implications for Reducing Chronic Disease Risk. Washington (DC): the National Academies Press (US).

37. Koushki M, Dashatan NA, Meshkani R (2018) Effect of Resveratro Supplementation on Inflammatory Markers: A Systematic Review and Metaanalysis of Randomized Controlled Trials. Clin Ther 40: 1180-1192. Link: https://bit.ly/2ZBzhjA

38. Magyar K, Halmosi R, Palfi A, Feher G, Czopf L, et al. (2012) Cardioprotection by resveratrol: $A$ human clinical trial in patients with stable coronary artery disease. Clin Hemorheol Microcirc 50: 179-187. Link: https://bit.ly/3e9ofGs

39. Chow SE, Hshu YC, Wang JS, Chen JK (1985) Resveratrol attenuates oxLDL-stimulated NADPH oxidase activity and protects endothelial cells from oxidative functional damages. J Appl Physiol 102: 1520-1527. Link: https://bit.ly/2XrhuJi

40. Bradamante S, Barenghi L, Piccinini F, Bertelli AAE, Jonge RD, et al. (2003) Resveratrol provides late-phase cardioprotection by means of a nitric oxideand adenosine-mediated mechanism. Eur J Pharmacol 465: 115-123. Link: Link: https://bit.ly/2WUs24z

41. Zhang H, Zhang J, Ungvari Z, Zhang C (2009) Resveratrol improves endothelia function: Role of TNFa and vascular oxidative stress. Arterioscler Thromb Vasc Biol 29: 1164-1171. Link: https://bit.ly/2LUnZyV
42. Hoffmann J, Haendeler J, Aicher A, Rössig L, Vasa M, et al. (2001) Aging enhances the sensitivity of endothelial cells toward apoptotic stimuli: Important role of nitric oxide. Circ Res 89: 709-715. Link: https://bit.ly/3bQ9V4c

43. Csiszar A, Ungvari Z, Edwards JG, Kaminski P, Wolin MS, et al. (2002) Aging induced phenotypic changes and oxidative stress impair coronary arteriolar function. Circ Res 90: 1159-1166. Link: https://bit.ly/3easT6Z

44. O'Leary KA, de Pascual-Teresa S, Needs PW, Bao YP, O’Brien NM, et al. (2004) Effect of flavonoids and vitamin $\mathrm{E}$ on cyclooxygenase-2 (COX-2) transcription. Mutat Res 551: 245-254. Link: https://bit.ly/2TwGSfG

45. Chao HH, Juan SH, Liu JC, Yang YH, Yang E, et al. (2005) Resveratro inhibits angiotensin II-induced endothelin-1 gene expression and subsequent proliferation in rat aortic smooth muscle cells. Eur J Pharmacol 515: 1-9. Link: https://bit.ly/2AUMh9W

46. Yang B, Ma S, Wang YB, Xu B, Zhao H, et al. (2016) Resveratrol exerts protective effects on anoxia/reoxygenation injury in cardiomyocytes via miR34a/Sirt1 signaling pathway. Eur Rev Med Pharmacol Sci 20: 2734-2741. Link: https://bit.ly/2AMbKSL

47. Deng R, Chow TJ (2010) Hypolipidemic, antioxidant, and anti-inflammatory activities of microalgae Spirulina. Cardiovasc Ther 28: e33-e45. Link: https://bit.ly/2AMbC5J

48. Ku CS, Pham TX, Park Y, Kim B, Shin MS, et al. (2013) Edible blue-green algae reduce the production of pro-inflammatory cytokines by inhibiting NF-KB pathway in macrophages and splenocytes. Biochim Biophys Acta 1830: 2981 2988. Link: https://bit.ly/36qPZDG

49. Agarwal B, Campen MJ, Channell MM, Wherry SJ, Varamini B, et al. (2013) Resveratrol for primary prevention of atherosclerosis: Clinical trial evidence for improved gene expression in vascular endothelium. Int J Cardiol 166: 246248. Link: https://bit.ly/2LOlv42

50. Militaru C, Donoiu I, Craciun A, Scorei ID, Bulearca AM, et al. (2013) Ora resveratrol and calcium fructoborate supplementation in subjects with stable angina pectoris: Effects on lipid profiles, inflammation markers, and quality of life. Nutrition 29: 178-183. Link: https://bit.ly/2WVkm23

51. Movahed A, Nabipour I, Lieben Louis X, Thandapilly SJ, Yu L, et al. (2013) Antihyperglycemic effects of short term resveratrol supplementation in type 2 diabetic patients. Evid Based Complement Alternat Med 2013: 11. Link: https://bit.ly/3e9mM2U

52. Martínez-Sámano J, Torres-Montes de Oca A, Luqueño-Bocardo OI, Torres Durán PV, Juárez-Oropeza MA (2018) Spirulina maxima Decreases Endothelia Damage and Oxidative Stress Indicators in Patients with Systemic Arteria Hypertension: Results from Exploratory Controlled Clinical Trial. Mar Drugs 16: 496. Link: https://bit.ly/2ywwgWY

53. Torres-Duran PV, Ferreira-Hermosillo A, Juarez-Oropeza MA (2007) Antihyperlipemic and antihypertensive effects of Spirulina maxima in an open sample of Mexican population: a preliminary report. Lipids Health Dis 6: 33 Link: https://bit.ly/2AS3AIB

54. Cheong S, Kim M, Sok D, Hwang S, Kim J, et al. (2010) Spirulina Prevents Atherosclerosis by Reducing Hypercholesterolemia in Rabbits Fed a HighCholesterol Diet. J Nutr Sci Vitaminol 56: 34-40. Link: https://bit.ly/2AULiXi

55. Poulsen MM, Vestergaard PF, Clasen BF, Radko Y, Christensen LP, et al. (2013) High-dose resveratrol supplementation in obese men: An investigatorinitiated, randomized, placebo-controlled clinical trial of substrate metabolism insulin sensitivity, and body composition. Diabetes 62: 1186-1195. Link: https://bit.ly/3ga16p

56. Crandall JP, Oram V, Trandafirescu G, Reid M, Kishore P, et al. (2012) Pilot study of resveratrol in older adults with impaired glucose tolerance. J Geronto A Biol Sci Med Sci 67: 1307-1312. Link: https://bit.ly/36nHlpL

57. Resveratrol Dose By The Annals of the New York Academy of Sciences. Rev Genetics. Link: https://bit.ly/2yoP762

Citation: Wang Y, Ocampo MF, Rodriguez B, Chen J (2020) Resveratrol and Spirulina: Nutraceuticals that Potentially Improve Cardiovascular Disease. J Cardiovasc Med Cardiol 7(2): 138-145. DOI: https://dx.doi.org/10.17352/2455-2976.000129 
58. Burns J, Yokota T, Ashihara H, Lean ME, Crozier A (2002) Plant foods and herbal sources of resveratrol. J Agric Food Chem 50: 3337-3340. Link: https://bit.ly/3bX0XII

59. Stervbo U, Vang O, Bonnesen C (2007) A review of the content of the putative chemopreventive phytoalexin resveratrol in red wine. Food Chem 101: 449457. Link: https://bit.ly/3eeHyOW

60. Joventino IP, Alves HGR, Neves NC, Pinheiro-Joventino F, Leal LKAM et al. (2012) The microalga Spirulina platensis presents anti-inflammatory action as well as hypoglycemic and hypolipidemic properties in diabetic rats. $J$ Complement Integr Med 9. Link: https://bit.ly/3c0EqEp
61. Miczke A, Szulińska M, Hansdorfer-Korzon R, Kręgielska-Narożna M, Suliburska $J$, et al. (2016) Effects of spirulina consumption on body weight, blood pressure, and endothelial function in overweight hypertensive Caucasians: a double-blind, placebo-controlled, randomized trial. Eur Rev Med Pharmacol Sci 20: 150-156. Link: https://bit.ly/2Twohk1

62. Cho S, Namkoong K, Shin M, Park J, Yang E, et al. (2017) Cardiovascular Protective Effects and Clinical Applications of Resveratrol. J Med Food 20: 323-334. Link: https://bit.ly/3bZugnA

63. Jeong SJ, Choi JW, Lee MK, Choi YH, Nam TJ (2019) Spirulina Crude Protein Promotes the Migration and Proliferation in IEC- 6 Cells by Activating EGFR/ MAPK Signaling Pathway. Mar Drugs 17: 205. Link: https://bit.ly/2A4z9hS

\section{Discover a bigger Impact and Visibility of your article publication with} Peertechz Publications

\section{Highlights}

* Signatory publisher of ORCID

* Signatory Publisher of DORA (San Francisco Declaration on Research Assessment)

* Articles archived in worlds' renowned service providers such as Portico, CNKI, AGRIS, TDNet, Base (Bielefeld University Library), CrossRef, Scilit, J-Gate etc.

- Journals indexed in ICMJE, SHERPA/ROMEO, Google Scholar etc.

* OAI-PMH (Open Archives Initiative Protocol for Metadata Harvesting)

* Dedicated Editorial Board for every journal

* Accurate and rapid peer-review process

* Increased citations of published articles through promotions

* Reduced timeline for article publication

Submit your articles and experience a new surge in publication services (https://www.peertechz.com/submission).

Peertechz journals wishes everlasting success in your every endeavours.

Copyright: (c) 2020 Wang Y, et al. This is an open-access article distributed under the terms of the Creative Commons Attribution License, which permits unrestricted use, distribution, and reproduction in any medium, provided the original author and source are credited.

Citation: Wang Y, Ocampo MF, Rodriguez B, Chen J (2020) Resveratrol and Spirulina: Nutraceuticals that Potentially Improve Cardiovascular Disease. J Cardiovasc Med Cardiol 7(2): 138-145. DOI: https://dx.doi.org/10.17352/2455-2976.000129 